\title{
Implementing 3D Printing Education Through Technical Pedagogy and Curriculum Development
}

\author{
https://doi.org/10.3991/ijep.v10i6.14859 \\ Ari Pikkarainen ${ }^{(凶)}$ \\ Lapland University of Applied Sciences, Kemi, Finland \\ ari.pikkarainen@lapinamk.fi \\ Heidi Piili \\ LUT University, Lappeenranta, Finland
}

\begin{abstract}
This study presents the development of a new pedagogical method, namely the model of technical pedagogy, for learning additive manufacturing (AM) due to the speed of the technological development. The speed of the technological development of AM is faster than of the educational one; curricula and teaching methods have to evolve all the time in order to keep up with the development. The implementation of AM into the mechanical engineering curriculum in Lapland university of applied sciences (Lapland UAS) in Finland is used as an example in this study. The aim and purpose of this study is to create a model of technical pedagogy which gives universities the possibility to integrate AM into their curriculum more efficiently. This happens by combining traditional pedagogy into technical subjects in curriculum development work. This study also presents the learning concept of AM which shows the learning to be inversely proportional to the requirements of AM. Identification of the learning process of AM help the educators to plan AM education more efficiently.
\end{abstract}

Keywords - 3D printing, additive manufacturing, pedagogy, technical pedagogy, curriculum, knowledge transfer

\section{Introduction}

Additive manufacturing (known also as 3D printing) is a technology where an object is built layer by layer from 3D CAD model with 3D printer [1]. 3D printing technologies are divided into seven different process categories according to the technology type and name according to SFS-EN ISO / ASTM 52900:2017 [2]. The process categories are binder jetting, directed energy deposition, material extrusion, material jetting, powder bed fusion, sheet lamination and vat photopolymerization. Material extrusion is the most used one due to its relatively low price and easiness of use compared with other technologies [1]. 3D printing started in 1984 when Charles Hull invented and patented the stereolithographic principle where UV light was used in curing photopolymer liquid layer by layer. This was the origin of vat photopolymerization technology. It was soon followed by powder bed fusion in 1989 where selective laser sintering (known as 
powder bed fusion of polymers) was used to sinter polymer particles together. Scott Crump from Stratasys patented fused deposition modeling technology in 1992 which was the start of material extrusion technology. Material jetting technology has its roots from the middle of the 1990's but the principle of jetting grew stronger especially by the development by the Objet Company in the 2000's [1], [3]. These construct the basis of polymer printing technologies discussed in this study.

Perhaps the largest impact on modern desktop size 3D printing happened in 2009 when the patent for material extrusion expired. This was the start for a new generation of $3 \mathrm{D}$ printers and to the development of desktop size printers. This ensured AM to be a solid part of engineering and other types of applications [3]. For example, in engineering education, this meant that AM could be reckoned as one manufacturing alternative within the traditional ones such as milling and turning. This happened through the increased variety of AM machines, especially by cheaper desktop size 3D printers which could be acquired for educational purposes more easily.

In the field of mechanical engineering, 3D printing opens up a broad area for learning since education and proper training is a necessity especially for the students and experts, who work with 3D printing [4]. One main function of universities of applied sciences (UAS) in Finland is to produce professionals according to the work life demands and demands [5]. Therefore, 3D printing offers the possibility for UAS to offer proper and practical AM education for work-life purposes through the graduated engineers.

One key component in learning the required skills (e.g. AM) is to operate with problem-solving processes. This is because work-life consists of different phenomena and problems which have to be handled with using the skills. The reality which work-life demands brings to learning can be implemented through problem-based learning addressing the problems and situations. The problem-solving process is based on finding information from the problem and constructing possible answers to the problem [6]. According to the experience of main author, 3D printing presents an excellent way to learn technology since learning by doing and handling problems during the AM process produces knowledge that the students can exploit in work-life situations. For example, the mechanical engineering students at Lapland UAS have described the learning of 3D printing, which includes the theoretical and practical part, to be efficient especially when the student can perform independent tasks with printers. Finding the reason to some problem makes the learning more versatile.

The aim and purpose of this study is to create a model which will combine the traditional pedagogical aspect of learning into the technical factors that need to be considered when arranging technical education through curriculum development. Based on the experience of the authors, the practices for learning AM in engineering are generally unorganized, every university performs AM teaching in their own way. Therefore, a need exists for a pedagogical model based on AM learning. This forms the problem statement identified in this study.

The literature considering learning AM in engineering education does not provide a solid model which would take the technical aspects into consideration in the pedagogical arrangements. The model created in this study is called the model of technical pedagogy. This model works as a guide for educators when planning or developing education around certain technology with more detailed technical issues. In addition, this 
study presents the implementation of AM into the curriculum of Lapland UAS mechanical engineering students and offers a view to inversely proportional learning of AM, which forms the foundation for understanding the implementation of AM education.

The theoretical information presented in this study work as a background for the model by justifying the usage of desktop size printer technology in engineering education due to its benefits (such as availability, price and suitability). Methodology used in this study is based on literature review and on the 13 years' experience of the main author as an educator of mechanical engineers and to the student feedback received from past 3D printing courses in Lapland University of Applied Sciences in Finland (Lapland UAS). The implementation of AM to the curriculum is based on to the mechanical engineering curriculum development work done in Lapland UAS between 2014-2017. The technologies under discussion in this article are material extrusion, vat photopolymerization and powder bed fusion which present the most used technologies in the polymer/desktop size printer area. In addition, these represent the AM technologies used in current Lapland UAS mechanical engineering 3D printing laboratory.

\subsection{Background for the study}

This overview creates the background for the study since the classification of 3D printing equipment is important when planning AM education especially in engineering. This section separates industrial printers from office/desktop size printers since concerning AM education, the price and usability of the equipment are important in acquiring equipment for educational purposes.

A division between the printer types according to their size and usage can be seen in Figure 1 [7].
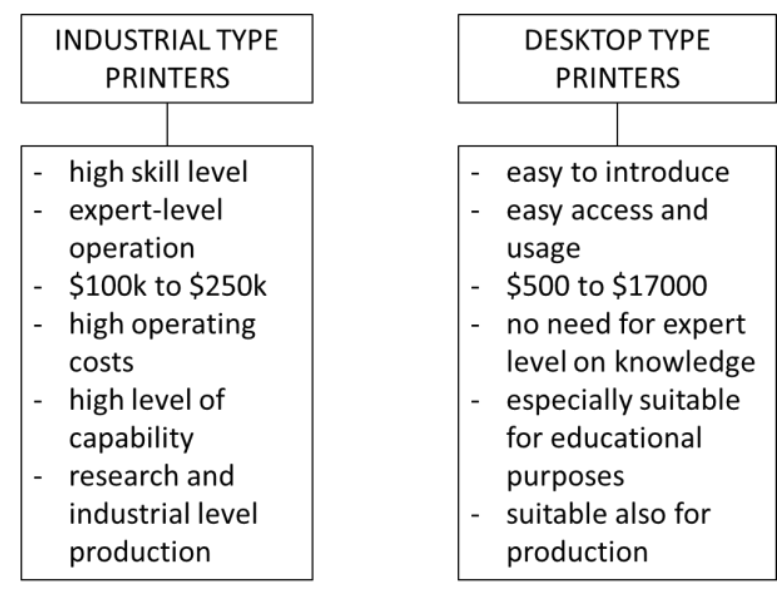

Fig. 1. AM printer type division [7]

This kind of division (see Figure 1) from the knowledge point of view is required in order to understand the requirements for using $3 \mathrm{D}$ printers. It is important to understand the requirements for educating engineers with $\mathrm{AM}$ contents. For example, it is 
important to make this division in engineering education when planning AM education from learning, usage or budget point of view. The technology should be accessible for the students and the threshold for learning and using it should be low in the beginning. This will be discussed later in this study as it presents the learning process in AM with respective to the requirements from the technology. This division (see Figure 1) helps in decision making when acquiring AM technology to the education. The differences between the types (see Figure 1) are discussed in following.

First group are so called conventional industrial type printers which are meant for professional use. Introduction of these printers requires a high skill level and the users are usually labeled as AM experts in their area. This higher level of technology cannot be used in the basic AM education of engineers due to the lack of experience of the students. The types of machines are not usually available for e.g. in student projects widely since it requires more knowledge, time and expertise to use these. These are very expensive, ranging from $\$ 100000$ up to $\$ 250000$ when discussing the base price of polymer printers. These devices need accessories so in total the price can reach $\$ 350$ 000. The operating costs are high and the machines are capable of industrial level of operation. The application is usually research, industrial level manufacturing or part of a manufacturing process. This shows that these types of machines are not necessarily the best option for adopting AM to engineering education. Especially when learning the basic principles of the technology is in the center. Therefore, the industrial type printers should be used in the final semesters of engineering and in more advanced student projects. The $3 \mathrm{D}$ printing projects are usually under a close inspection and reviewing which limits the user base. This means that the printing work is supervised and it cannot be used e.g. in independent student projects in earlier semesters. Therefore, the typical user is a last stage student with good experience with the machine, making his/her BSc (Bachelor of science) thesis or other research work. The 3D printers are usually placed in some sort of center of research or excellence [7].

Desktop level printers (see Figure 1) are targeted to normal consumers and regular users. This makes these types of 3D printers more suitable for engineering education when e.g. adopting AM to curriculum due to the lower use threshold of the technology. The lower price enables the acquisition of multiple printers and through this more students can be reached in courses. Desktop level printers are easy to use and they require low skill level in the beginning. Some printers such as the vat photopolymerization printer Form 3 from Formlabs require only a couple of minutes for start the printing work, even without less experience. Since the purchase price of desktop level printers is usually around $10 \%$ compared with the industrial type printers, user can acquire more than one printer. If one printer fails or has downtime, the work will not stop due to failure or maintenance etc. [7]. The price range is very wide for the desktop type printers: the cheapest material extrusion printers start from $\$ 500$ and more advanced selective laser sintering printers are around $\$ 17000$. This means that in education multiple printers can be used simultaneously and the entire student group can learn by doing at the same time without having to wait for available printer. This is important especially in the courses where AM in introduced to students; by connecting the theoretical lectures with practical work with the printers as soon as possible, the students are capable 
of connecting the AM knowledge into practice more efficiently. The development of AM technologies can be seen in Figure 2 [8].

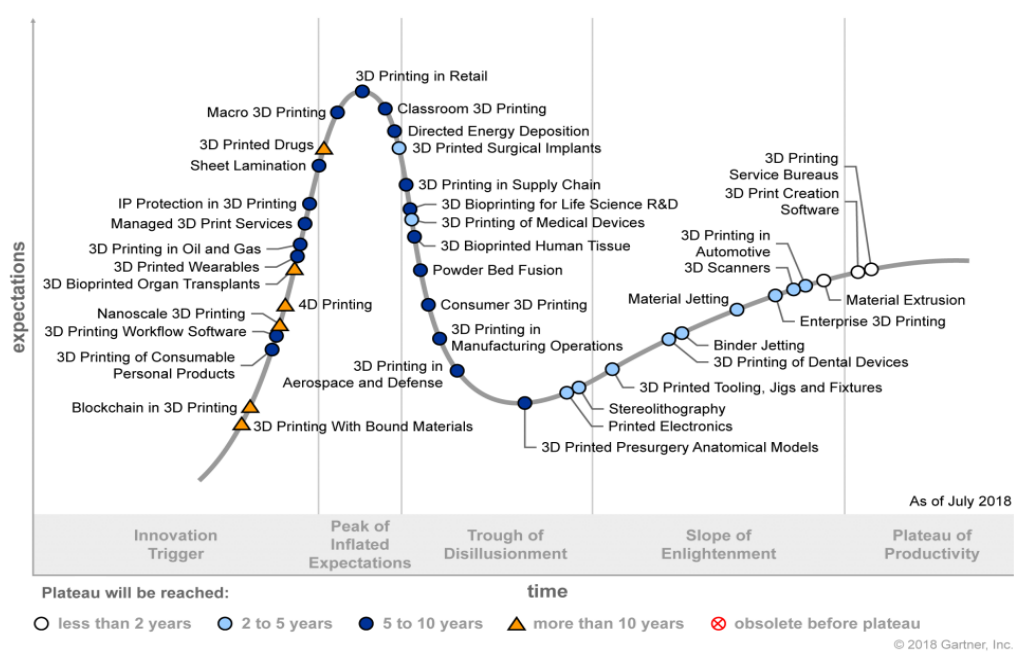

Fig. 2. Gartner hype cycle for 3D printing [8]

Gartner hype cycle (see Figure 2) for 3D printing presents the maturity and potentiality of certain technology. It explains the evolution of 3D printing technologies in five stages and gives an insight about the business potential of the technology. It helps companies to build their investment strategies and reduce risks in investments [9]. The hype cycle shows "consumer printing" to be passed the peak of expectations and is beginning to stabilize itself as one of the normal innovations in society [8]. Gartner hype cycle (see Figure 2) presents the basic polymer printing technologies to be already common and proved technologies in AM sector (such as material extrusion and stereolithography which can be listed as a part of the consumer printing term). These technologies belong to the desktop size printer category (see Figure 1) and therefore Gartner hype cycle proves that these technologies are suitable for educational purposes also.

The division between printer types (see Figure 1) form the starting point when planning AM education in this study especially from the user and application point of view. Even though the division may be steep, it helps to target the topics and issues in this paper through desktop size printers and their importance in AM education.

There are still a lot of differences, especially in integration and in functions between these two divisions (see Figure 1) (e.g. in educational environments containing machines from both categories) but these two are the main categories currently in AM. The same division can be seen in the terminology; the term "additive manufacturing" is used when discussing industrial applications and the term "3D printing" is used when the consumer point of view is discussed even though they mean the same thing. 3D printing is starting to be the regular term when discussing the technology [10]. For example, 3D printing is more commonly used term in engineering education especially in the name of the courses but when teaching the theoretical basis, additive manufacturing 
and other standardized terms are used. 3D printing term reaches more people and especially the students who are at the beginning of learning AM.

\section{$2 \quad$ Literature Review}

The topics presented in this literature study present the connected literature in the light of different applications in 3D printing that are used in education. The connection between AM education and industry and companies is important since it is the key component in planning AM education based according to work life demands. This review presents the challenges in AM education which present the identified problem statement in this study; a comprehensive pedagogical model is needed to develop AM education in engineering.

\subsection{Applications of 3D printing}

3D printing as a technology has rooted itself to the society and media; quite many people assume themselves to be 3D printing experts when they have seen or used such a device; usually only one type of machine has been used [11]. This seems to be sometimes the general assumption but in spite of this, 3D printing has its applications and experts who are using the technologies in far more advanced situations, which is the reality of AM. To understand better the different applications and the implementation of them in education, a detailed categorization of the applications must be created. This categorization can be presented through three main applications as seen in Figure 3 [1], [10], [12].

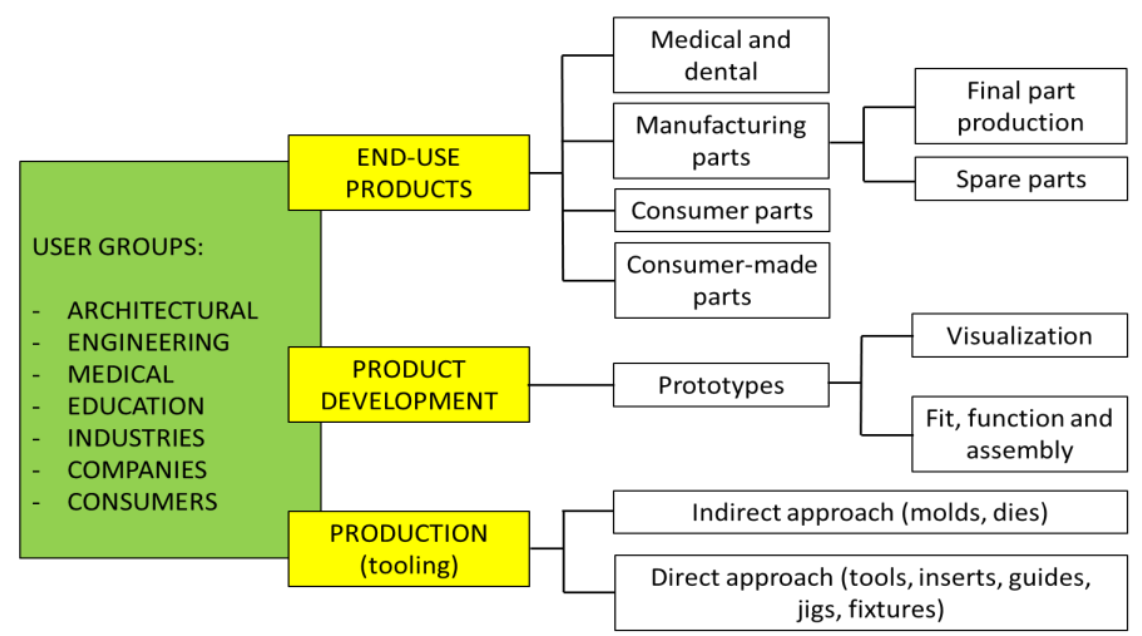

Fig. 3. Categories of AM applications and the possibilities to use them e.g. in education [1], [10], [12] 
Figure 3 shows how the main user groups can be divided into the industry, companies, educational sector, research and to people, who use it e.g. for their own purposes or as a hobby. The figure can be used in education since the examples of the applications can be used directly e.g. as activities in 3D printing courses. These user groups include several different areas where 3D printing brings extra value or is sometimes the only reasonable solution to achieving desired educational goals.

Dividing the AM applications into different categories (see Figure 3) can be done in different ways and there is no standard for the presentation. This model is meant to be universal for many of the user areas of additive manufacturing. Different sources use categories such as prototyping, visual aids, final part production, just a few to mention. For example, for learning assignments with a certain goal, the categories offer a good way to target the assignment to certain area of engineering. In this study the applications of AM have been divided into three main categories (see Figure 3), which represent the most common way to define the usage of AM in different sources [1], [10], [12]. When developing AM education, these three categories serve as a starting point e.g. in drafting the learning objectives for courses from AM knowledge point-of-view. The main categories of different AM applications (see Figure 3) are end use products, product development and production (tooling).

End use products (see Figure 3 ) was the continuation from the original idea of rapid prototyping. As the technology developed in the 2000s, the machines were capable of produce products and components that were suitable directly to a selected application (so called direct manufacturing). This was especially one start point for the term additive manufacturing instead of rapid prototyping, which was the previous used term [1]. Many of the fabrication types, such as functional parts and spare parts, fall into this category. For example, one main point to learn manufacturing methods is to produce objects that can directly be used in desired application. By investigating and implementing this possibility with $3 \mathrm{D}$ printing, the students will learn that $\mathrm{AM}$ is one considerable manufacturing method among the traditional ones such as turning and milling.

Product development (see Figure 3) is probably the best-known application for the technology. 3D printing brings extra value to the design process by offering more possibilities in creating complex geometries and keeping the design work versatile [13]. This includes making visual hand-held versions of the design instead of 3D CAD models to help the designers and users to visualize the product better [1]. For example, product development is one of the main areas in Lapland UAS mechanical engineering education is and 3D printing offers flexible, affordable and logistically easy way to visualize the products and e.g. make prototypes for testing and viewing the product features.

Production (tooling) (see Figure 3) offers the possibility to produce tools and tooling aids for production. Molds and dies are used when casting or injecting products and different inserts, fixtures and jigs ease the manufacturing process when producing evenquality products [10], [12]. For example, when learning casting methods, 3D printing offers the possibility to learn tool production without the need for manufacturing them with traditional methods. This improves e.g. the understanding and learning of production planning. 


\subsection{Impact on companies and industry through education}

3D printing has become a trend word and it can be noticed in everyday life and even in daily talks. 3D printing has rooted itself to the daily life since it has increased its visibility in the media, especially through its increased possibilities in the manufacturing area [14]. This sets demands and expectations for engineering education. For example, courses in engineering education are expected to contain 3D printing as default. Depending on the degree of education, the demands for the technology (e.g. equipment types) come from the required level of AM knowledge. Engineering education have to keep up with the demands from work-life representatives who are using AM in their functions and employ graduated engineers.

As the standardization of AM is progressing, some parts of the AM process can be validated but still the heterogeneity of printed parts and production time limitations present challenges for raising AM to the same level with the traditional manufacturing methods [15]. This means for education that AM must be researched in order to increase knowledge about AM and to decrease the gap between AM and the traditional methods. This is important since the graduated engineers export the information to the work-life.

The direction is correct; the manufacturing sector is becoming more and more aware of the possibilities of the technology since AM is used in many sectors such as industrial, medical and military, just a few to mention [10]. This means that AM must be implemented e.g. in engineering education firmly to the engineering curricula in order to fulfil the demands of the manufacturing sector. One key issue to address is how to ensure that AM knowledge reaches the manufacturing industry in a way which helps them to solve these challenges in adopting AM into the production processes. In Lapland UAS, the AM knowledge reaches the manufacturing industry through graduated students, R\&D-functions and through separate continuing education courses planned to be held for work-life representatives in the future. However, this study concentrates in implementing AM in Lapland UAS mechanical engineering studies and R\&D-functions, continuing education issues are not discussed here.

According to the experience of the main author as an educator, one important key factor enabling this is the principle of knowledge transfer, which is illustrated in Figure 4 [6], [16], [17]. This is based on the long collaboration between the main author's university (Lapland UAS) and the industry around the university's area (mainly paper, pulp and steel industry). This collaboration covers research projects, BSc theses and student employment (during the studies as internships and after the graduation) to the industry, just a few to mention. The dialog between the university and industry gives valuable feedback about the engineering education provided in the university.

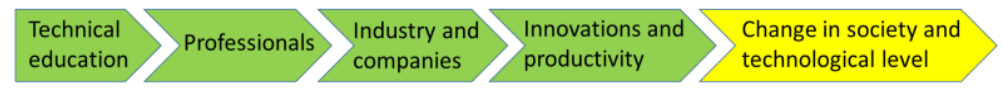

Fig. 4. Knowledge transfer principle [6], [16], [17]

Figure 4 presents the idea of knowledge transfer, which shows the path from technical education to the required target (in this case the companies and manufacturing industry). As mentioned in this study before, the main function of universities of applied 
sciences is to produce professionals and experts to industry and companies, who possess the latest information about modern manufacturing technologies, for instance [6]. For example, the information provided for the students must reply to the requirements of companies and manufacturing industry in order to strengthen the collaboration.

According to the experience of the authors, the requirements from companies and industry usually derive from the need for innovations and improvement in the operation of the enterprises. Their relationship to universities is based on collaboration. Companies and industry can benefit through common projects based on a need, for instance to develop something, which is one of the most common ways to do collaboration. This means that the curriculum in engineering education must be capable of intake topics from collaboration partners and enable students to function in work-life projects.

If this is looked e.g. from knowledge point of view, the information produced in engineering education is not always easy to adapt to the demands of companies and industry. Reason for this is usually the professional link missing between the education and work-life; the collaboration requires active people who work in the interface. If the teaching personnel is not involved e.g. with R\&D projects, the low level of contact to work-life may complicate the adaptation of information. One way to solve this is to ask project work topics directly from the companies and industry and use contacts the personnel have.

Therefore, the employment of educated professionals is an important key factor in transferring the knowledge [16]. The role of the universities is to support and contribute to the development of innovations and sustainable economics in enterprises. As the companies and industry employ the educated professionals, it leads to new innovations in the companies and industry since universities can be seen the producers of the required knowledge [16], [17]. This sets demands and pressure e.g. to engineering education since the content of the learning must be modern and meet the requirements from work-life. The UAS sector must apply the modern practical methods in the learning and the didactical methods must bend to these. Based on the experience of the main author, this ultimately leads to positive change in society as viability increases through economic growth and technology advances through the knowledge transfer in companies and industry.

\subsection{D printing and engineering education - Challenges and possibilities}

The growth of $3 \mathrm{D}$ printing has been enormous since the popularity of desktop size $3 \mathrm{D}$ printing is increasing all the time due to its relatively low price and easy accessibility (e.g. material extrusion technology). Desktop size 3D printing is closing the gap between industrial type printing from quality and machine reliability point of view. This has boosted the usage of AM in the educational sector since these factors facilitate the acquisition of AM to different purposes [1], [10]. Looking from educational perspective, this benefits e.g. the engineering education since now it is possible to acquire more sophisticated and accurate desktop size printers (e.g. vat photopolymerization and powder bed fusion of polymers) for teaching and learning.

In this study, the Lapland UAS mechanical engineering BSc level is used as an example. The need for developing the connection between $3 \mathrm{D}$ printing and engineering 
education derives from the 13 years' experience of the main author as an educator of engineers and from the collaboration with the industry of Lapland UAS area (paper, pulp and metal industry). The usage of 3D printing in the manufacturing industry in the area of Lapland in northern Finland is not yet very widely used (or partially at all). By connecting 3D printing to the Lapland UAS mechanical engineering education, it increases the awareness in Lapland area to utilize 3D printing in the manufacturing processes through knowledge transfer. Figure 5 (derived from Figure 4) presents the demands that the knowledge transfer model (see Figure 4) brings to engineering education.

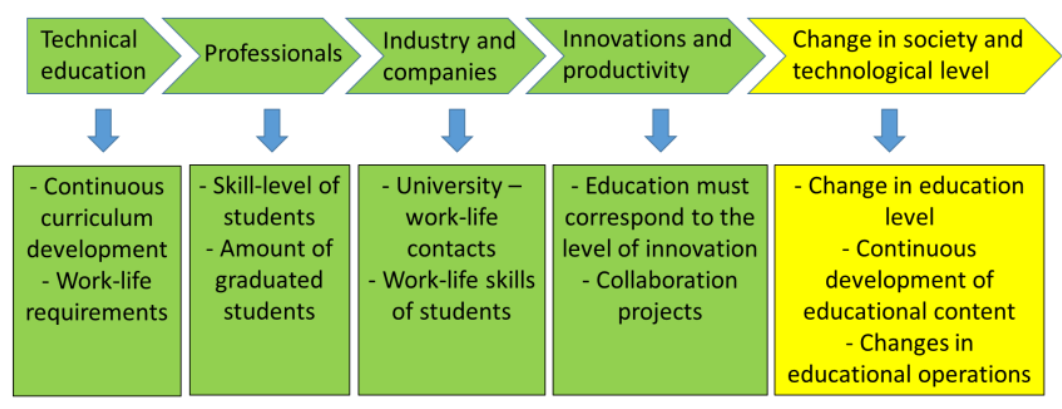

Fig. 5. Demands set to education by knowledge transfer factors. Modified from [6], [16], [17]

The arrangement of technical education (see Figure 5) requires continuous curriculum development in order to keep up with technical evolution. The requirements from work-life must be met through curriculum in different courses and learning events. The knowledge is transferred through educated professionals and therefore graduated students must possess required skill and knowledge level. The university must be able to produce sufficient amount of these skilled graduates every year. When finding employment in companies and industry, the university's work-life contacts are important and the students must possess required work-life skills learnt during studies (usually in practical internship periods). As the graduated students are working in companies, they produce innovations and participate to the increasement of productivity. This means that during the education they should learn to make innovations and know the meaning of productivity (hence the studies related to business and economics are important). Ultimately, the change in society and technological level means that the education must change in order to keep up with the social and technological evolution.

If the industry or companies do not recognize the AM possibilities, one function of universities is to encourage them to use AM. The collaboration between the university and industry / companies is the most active in internship possibilities in companies, BSc these processes, common development projects and in continuing education [18]. This indicates that the foundation of engineering education is vital and by including AM in the educational core, the knowledge transfer possibilities of AM will increase.

Based on the main author's observations, the manufacturing experts who have had their professional education 10-30 years ago, the studies did not include AM. This indicates that the future experts possessing necessary skills, need a curriculum that takes 
the principles of additive manufacturing (also in practice) into account at many levels of qualification, especially in under- and postgraduate level [19]. Based on the observations of the main author, the education of engineers in northern Finland has always leaned more to the requirements of the industry based on the features of the manufacturing processes. Therefore, one function of the Lapland UAS mechanical engineering degree is to increase the AM knowledge in the area although the traditional bulk product manufacturing industry the main focus. Bulk products consist of stainless-steel strip, paper and packaging products such as cardboard. There are several companies, which perform e.g. product development, who could benefit from AM in northern Finland. According to the main author's experience, there are also many companies who function as a subcontractor to the industry so by implementing AM into the engineering education, the possibilities and benefits of AM can be detected in the subcontracting companies. This can be seen in Lapland UAS from the lack of AM topics which could be used in student projects. The engineering education should encourage companies to use AM through common projects (e.g. through prototype production for some part that need to be designed). This way the knowledge about AM would increase in Lapland area of Finland.

When looking at the recent development of additive manufacturing, especially the speed of it, the educational sector is facing a challenge adopting the AM knowledge to the curricula [19]. According to the experience of the main author, the turnaround of a curriculum takes four to six years (under-graduate / post-graduate level) and during this time, the technology (e.g. AM) might have developed greatly already. The adaption of curriculum development into the speed of technological development of AM presents a challenge. Some educational institutions have solved this by arranging continuing education in the form of part-time training or short courses [19]. These are very good methods to implement a modern view into practice and this way the education can be targeted to a specific group of users. According to the main author's experience, curriculum is usually tied to a certain timetable and the course contents are planned at least half a year or even one year beforehand. Therefore, the curriculum should be flexible and intake "last-minute" topics e.g. through free elective courses but also fix the topics to the mandatory courses concerning the most important modern technologies. This is the reason why the curriculum development must be inspected according to the desired technology (e.g. AM).

\section{Results}

\subsection{Creating curriculum considering AM education}

The implementation of AM into the engineering education can be approached by opening up the basic process of developing a curriculum in Lapland UAS. The main author has acted as the main responsible teacher (guiding a team of teachers and R\&D personnel during the development work) in renewing Lapland UAS mechanical engineering curriculum in 2014 - 2017. As a result, Lapland UAS mechanical engineering degree started in 2017 with new curriculum. The previous curriculum leaned more to 
separate courses targeting in specialization areas together with basic studies. There was no specific plot implemented in the curriculum besides addressing the main areas of the degree such as engineering design or maintenance through specialization studies. The professional studies were divided into special areas and part of them were elective for students to choose from. A new structure for the curriculum was introduced to enhance the concentration to the skills of a student and knowledge-based learning as presented in Figure 6 [20].

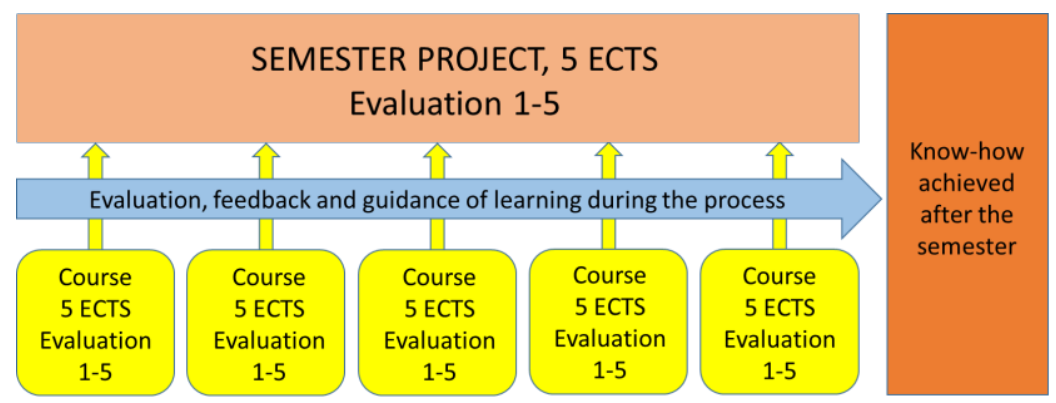

Fig. 6. Semester structure of the new curriculum [20]

Figure 6 presents the new curriculum dividing the four-year studies into eight semesters. In the center of each semester is a project, which collects the skills and knowledge acquired during the semester. The other courses during the semester work as supportive elements to the project offering information e.g. from mathematics, engineering design or other subjects. The know-how increases during the semester and the student achieves required skills after the semester [20].

The curriculum development followed Lapland UAS curriculum process which uses core content analysis in defining the central themes, contents and learning objectives. Core content analysis aims to define the themes, contents and learning objectives, which are derived from competences. Competences are partially pre-defined (general competences which are common e.g. for every mechanical engineering degree in Finland) and partially created to a specific degree. The process aims at balance the scope and requirements of the degree in relation to the pursued know-how [20]. During the curriculum planning work, the main author noticed that the process could also be used in implementing a certain technology into the curriculum since curriculum is the main tool for arranging engineering education. The curriculum model does not have to be generic (as it usually is) but a certain set of studies (e.g. AM) can be planned through the model by making it more accurate to match the AM technology as an example here. Through this, it is easier to notice where, when and how AM must be included in the process. This is one of the main observations of this study and it works as a background for the model of technical pedagogy developed in this study.

Even though the curriculum development process seems to be quite straightforward, it gives freedom to define the specific learning objectives and competences, which are included in the implementation plans of courses. After the startup of the new curriculum, an idea started to brew to implement AM more efficiently into the curriculum and 
to develop improved curriculum process for this purpose. In this study, AM presents the technology to be included in the curriculum.

The process of creating the curriculum can be divided into stages where certain actions are taken in order to produce necessary information. The basic structure of the process is presented in Figure 7 [20].

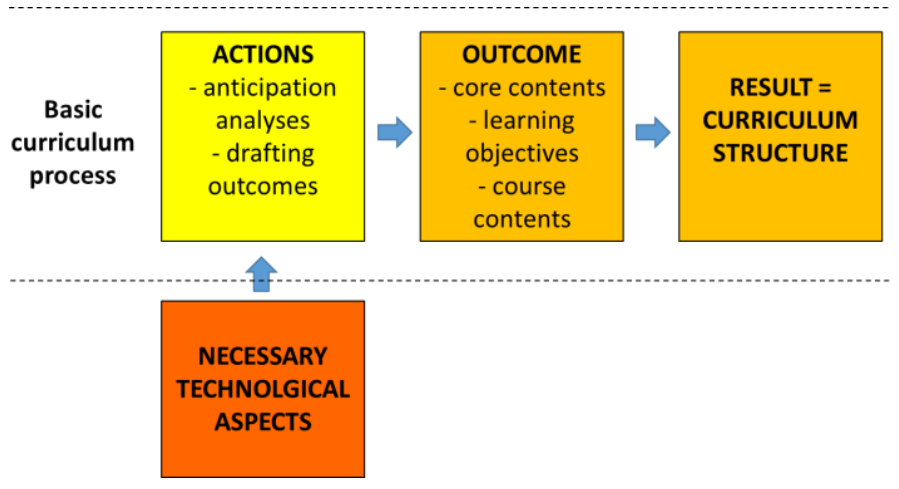

Fig. 7. Basic structure of the curriculum process with added technology. Modified from the Lapland UAS curriculum process [20]

The actions (e.g. core content analysis) (see Figure 7) are done in order to produce a certain outcome. The outcomes, such as learning objectives, work as the platform for creating the course contents. The technologies to be included (e.g. AM) are the ones that will be implemented to the curriculum. As an output (see Figure 7), the result presents the final structure for the curriculum containing the courses, timing of the courses during the semesters etc.

The basic curriculum process (see Figure 7) is used in implementing AM to Lapland UAS mechanical engineering degree. The following Figure 8 presents a detailed model of the curriculum process (see Figure 7), which includes the AM perspective. The model structure comes from the Lapland UAS curriculum process model [20].

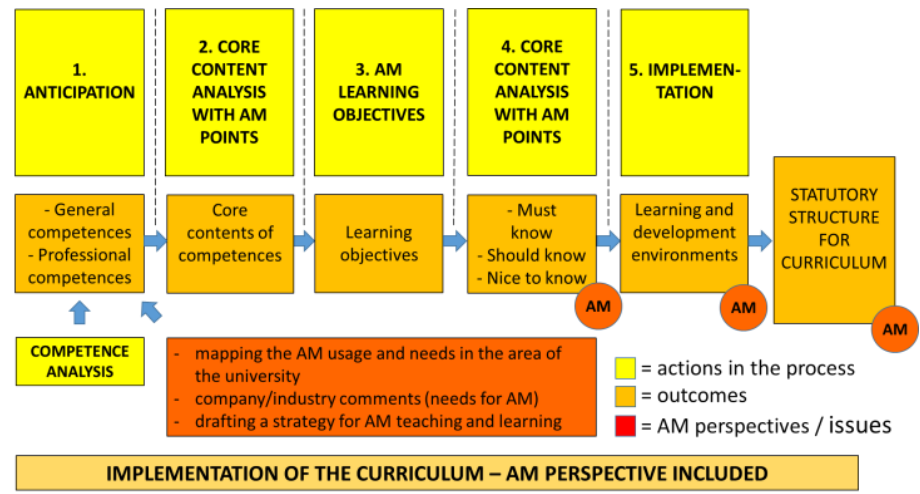


Fig. 8. Curriculum process with AM perspective. Modified from the Lapland UAS curriculum process [20]

Figure 8 shows the modified Lapland UAS curriculum process where the AM perspective has been included. The model shows where and how AM perspective must be included in the planning work. AM is the technological key point here since when designing a "technological" curriculum, skills and different perspectives are required in order to produce engineers who are capable of creative and versatile problem solving [21]. The following presents the description of the curriculum process first without AM perspective:

1. Anticipation (see Figure 8). The process starts from general competences, which are recommendations from the NQF in Finland (National Qualifications Framework). These include factors such as learning skills, ethics and international expertise [22]. Professional competences come from the demands of the industry and companies but also from the experience and results from previous curricula. These competences are meant to describe factors needed to perform certain work tasks such as potential, ability and qualification [20]. One important factor in planning the professional competences is to include the views of the industry and companies, which represent the "customer" in the process [20]. This happens by making a questionnaire to several partners from work-life and asking, what kind of skills and learning objectives are needed and expected in their operations.

2. Core content analysis, learning objectives (see Figure 8). The competences are analyzed and formed into core contents; this stage transforms the competences into learning objectives [20]. For example, in Lapland UAS mechanical engineering degree learning objectives such as the "ability to do mechanical measurements" or "understanding the failure mechanism of a certain machine" presents the skills the students will achieve during their studies.

3. Core content analysis (see Figure 8). These learning objectives are analyzed and categorized into three in the second core content analysis according to their importance; must know, should know and nice to know (e.g. must know: the student will know the basic rules of tolerances in technical drawings). These learning objectives are integrated into the course implementation plans, which act as a manuscript for arranging the course [20]. This stage forms an order of importance to the skills and helps to arrange the teaching for the subjects.

4. Implementation (see Figure 8). The implementation of these learning objectives happens in different learning and development environments such as laboratories, project work situations or in student projects [20].

As an output (see Figure 8), the statutory structure of curriculum is created presenting the four-year content of studies and learning objectives [20]. The structure comes from the University of Applied Sciences law in Finland and Lapland UAS degree regulations including basic, professional and free-choice elective studies, practical training and thesis [20]. This way the graduates will have the required expertise based on the demands of the same field in which they will be working after the graduation. The type of the new curriculum is knowledge-based and it forms the foundation of organizing 
learning [6], [20]. Problem-based learning forms the core of the learning process where the issues, phenomena and problems from real-life situations (such as an assignment from certain company) are handled and solved [6].

This kind of curriculum process will be used for implementing required AM skills into learning in Lapland UAS. According to the main author's experience, this is an efficient and organized methods to arrange engineering education and it offers a good way to view the engineering from broad perspective. Especially one of the most important part, the feedback from the companies and industries, can be included in the implementation plans of courses through partner questionnaires and work-life projects during the four-year period. This enables the equivalency of the engineering education to work-life demands.

Besides the regular engineering skills, the AM perspective must be included in the curriculum when the knowledge from AM will be transferred to companies and industry. When implementing AM principles into a curriculum process (see Figure 8), the following key factors should be considered according to the curriculum stages:

1. Anticipation (see Figure 8). This includes the demands of the industry and companies regarding additive manufacturing. First, the AM usage should be mapped in the area of the university by mapping the companies that are using or planning to use $\mathrm{AM}$ in their functions. This requires active conversation with key partners from work-life through e.g. BSc theses, common projects or R\&D operations. A separate, targeted questionnaire can be sent to selected work-life representatives if there is no information available about the AM requirements and usage of the partners. The university should develop a strategy for implementing AM into their curricula; what the goals are for AM teaching and learning in the long run, what AM technologies are used, what skills must be acquired, what kind of collaboration could be done with the companies etc. When analyzing the competences, the companies should be taken with to the review process so that they can give comments. From an educational point of view, the quality of the education can be ensured this way since the competences can be targeted more detailed. This can be seen in education as increased connection to work-life topics.

2. Core content analysis, learning objectives (see Figure 8). The core content descriptions should be created in a way that they could be implemented e.g. into laboratory courses and they would match the requirements from industry/companies. Especially, when the learning objectives are drafted into sentences describing the learning objectives, they should include the required AM technologies as well as materials. The objectives such as "the student knows the principles of AM technologies" and "the student is capable of working independently with material extrusion technology" are the same descriptions for learning outcomes and work-life demands.

3. Core content analysis (see Figure 8). These AM skills and learning objectives drafted in stage 2-3 are analyzed and put into order according to their importance. The importance is defined from the basis of the demands (e.g. comments from work life) and according to the AM strategy of the university.

4. Implementation (see Figure 8). Functional curriculum needs modern AM environment; the equipment must meet the demands set by the competences. If a company 
already uses a certain AM technology, it should be addressed in the learning situations of the topic. This can present a challenge to the education since the industry and companies use usually industrial style AM machines which can be too expensive to be acquired for the school. Therefore, the desktop size and reasonably priced alternatives are important. The work done in the AM environment should match the knowledge-based foundation of the curriculum; this can be achieved by having assignment topics from the work-life. If the learning requires more advanced equipment, one way to solve the problem is to arrange projects or collaboration with companies or other universities with industrial-type printers. The students could then work with equipment that is more advanced and the company and university would receive results through student work.

As an output (see Figure 8), the curriculum is constructed containing the courses and their timing within semesters. The placement of the courses and AM information must be planned carefully since the AM knowledge must grow during the four-year curriculum and cut through the required areas of mechanical engineering. This way the curriculum produces study content from AM, possibilities for practical training in AM learning environments and free-choice electives concerning AM. It can also act as a substrate for BSc theses producing research and development topics from AM.

\subsection{The learning of $\mathrm{AM}$ in engineering}

This type of curriculum structure (see Figure 6) fits very well for AM education purposes since the learning of AM consists of a theoretical basis and practical work. Practical part of the learning happens in laboratories (e.g. in laboratory courses) and learning environments with the AM machines [23]. For example, this enables the planning of semesters that are more targeted to AM through the curriculum. When a project (see Figure 6) is in the center of the semester, the project topic can contain AM perspective. The courses during the semester (including AM) support the realization of the project. This way the whole semester can be AM oriented.

According to the main author's experience, the production of 3D printed part is relatively easy at its best but the AM still has a lot of challenges such as the versatility of 3D printer software, unexpected problems in the printing process and the lack of standard for the safety of 3D printing (e.g. particle emissions, material handling). In different 3D printing courses held in Lapland UAS, the process of learning has usually followed the same kind of path, which derives from facing challenges in the actual printing process along with the theory connected with the subject (e.g. finding out the reason for nozzle collision to the part during material extrusion). Based on the experience from the courses, usual reason is the insufficient adhesion of the first layer with the printing platform causing the separation of the print from the platform. This leads to the nozzle collision with the part and to the print failure.

This happens usually in the beginning of the learning process, where the amount of problems is inversely proportional to the experience with the printers. Without sufficient experience from the common problems and failures, the student is the most likely 
to face them in the beginning without the ability to prevent them before they happen (e.g. with correct design or machine settings).

According to the main author's experience, $3 \mathrm{D}$ printing is a technology which cannot be learned through plain theory. Therefore, problem-based approach is an efficient way to learn AM. This principle of comparing the amount of problems with the user's experience can be seen in Figure 9.

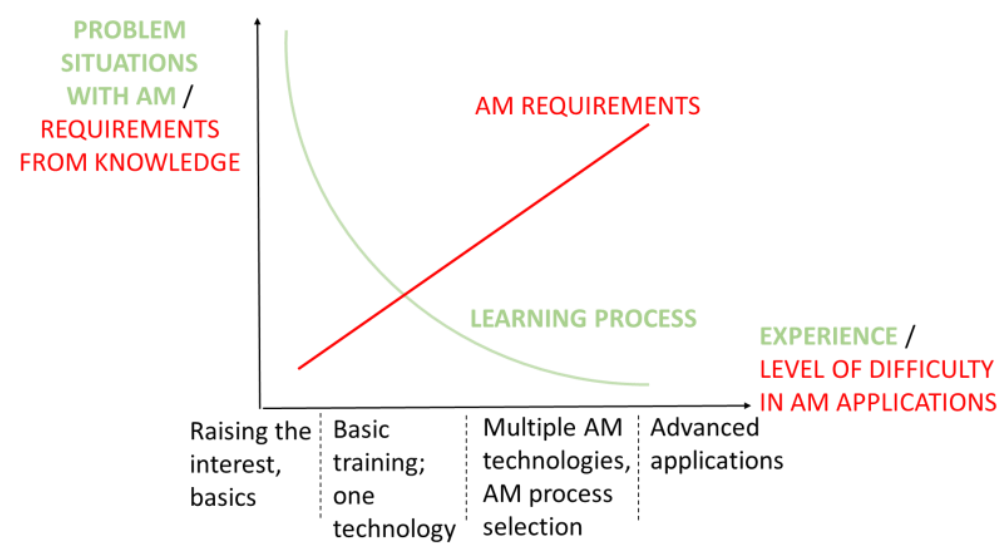

Fig. 9. Inversely proportional learning of AM

Figure 9 presents the idea concerning AM learning and its requirements. The lighter green curve presents the inverse learning process; due to the lack of knowledge and experience, problems appear more easily in the beginning. This is a result from the student's understanding about his/her own problem-solving skills and from the amount of education related to the problem-solving skills [24]. Therefore, successful adoption of new technology requires education from the area. Education usually starts from the theoretical aspects but learning by doing has presented to be an important part in supporting the education. As the experience develops, the user is capable of handling the more difficult situations independently. According to the experience of the main author, the darker red line (see Figure 9), is used to describe the requirements that users face from AM technology. The line is steep since the further the students proceeds in learning certain AM technology, the more experience and knowledge it requires.

According to the experience of the main author, based on 3D printing courses held for Lapland UAS mechanical engineering students, the AM requirements in the learning process can be described at four levels (see Figure 9): 1) raising the interest, 2) basic training, 3) multiple AM technologies and 4) advanced applications.

At the first level (see Figure 9), requirements from AM technology point of view are low (e.g. introducing material extrusion printing is rather simple) but as the situations progress into more advanced situations (e.g. more complex situations in the printing process with the powder bed fusion of polymers), the requirement level rises. The learning should be based on simpler things at the beginning of the process; this stage is meant to raise the interest and familiarize the user with the technology. This includes the 
introduction of the technologies and design principles, showing different cases from AM technologies. This lays the ground for the AM learning and raises the motivation to learn.

The second level (see Figure 9) introduces the user into the practical work. One good way is to do this through material extrusion technology since the threshold using it is lower than with the other technologies. This is usually the point where most of the regular users are; they use material extrusion in producing printed parts and at the same time the knowledge increases about the design principles and technology. This is the point where many educational units stay in their AM education and it is completely reasonable and accepted since using material extrusion offers many advantages with relatively low usage and maintaining costs. This level can be taken forward with just one technology but at some point, the limitations of one technology become an obstacle and prevent the student in progressing concerning the AM spectrum.

The third level (see Figure 9) is where several AM technologies are introduced (e.g. material extrusion, vat photopolymerization and powder bed fusion of polymers). The students have to reflect the product idea on the actual usage purpose and think (through AM process selection methods), which AM technology is the most reasonable to be used in this situation. This is the threshold that separates the regular users from advanced/expert users since using multiple technologies enables the possibility to define specific product features (e.g. material properties, accuracy, surface finish and usability).

The final fourth level (see Figure 9) is the advanced level; the student can work independently with multiple technologies and learn new AM technologies. The learning threshold is lower in this stage (the student possesses sufficient experience already from AM in order to learn new technologies more easily). This leads into advanced AM applications, where the possibilities of AM can be fully used and understood. This level is so called the industrial level, which has to be achieved in order to produce experts for the industry and companies.

Based on the experience of the main author, this model (see Figure 9) help in identifying the phases of the AM learning process and to create AM strategy through identifying the desired target level of expertise for the education.

\subsection{Creating the technical pedagogy model}

The term technical education is the de facto term usually used when discussing educating professionals and producing knowledge to different technical areas, especially when viewing the education of engineers [25]. It covers most of the technical areas but does not offer a clear solution for the pedagogy of certain technical area. This is because every university uses their own curriculum and methods in arranging the education. Most of the professional competences are not standardized in Finland in the University of Applied Sciences sector. This reflects on the main author's experience in educating mechanical engineers; the traditional pedagogical education of teachers offers good tools for arranging the learning process but is does not handle the technical details. Usually, the details are left for the teacher to apply in the best possible way according to the curriculum of the degree. 
When looking at the education of engineers more detailed, the term engineering pedagogy define the pedagogical arrangement of educating engineers. It operates in the interface between the technical side of engineering and traditional pedagogy and education [26]. This offers a detailed way to view the technical education but more accurate model is required when learning a certain technology (e.g. arranging AM education). This shows the gap in the current literature since teaching technical and detailed subject such as AM, there is a need for this kind of pedagogical model.

In order to identify the construction of AM based education and curriculum, a description of more targeted pedagogy must be created. This derives from the main author's experience in curriculum development and from the gap in the current literature. The implementation of curriculum with AM perspective (see Figure 8) form the foundation for the structure of engineering education and gives the core content to courses [20]. For the actual implementation of AM education in different courses and learning events, teachers and educators need more detailed model for arranging AM education from a pedagogical point of view. A starting point for identifying the factors for the model can be seen in Figure 10.

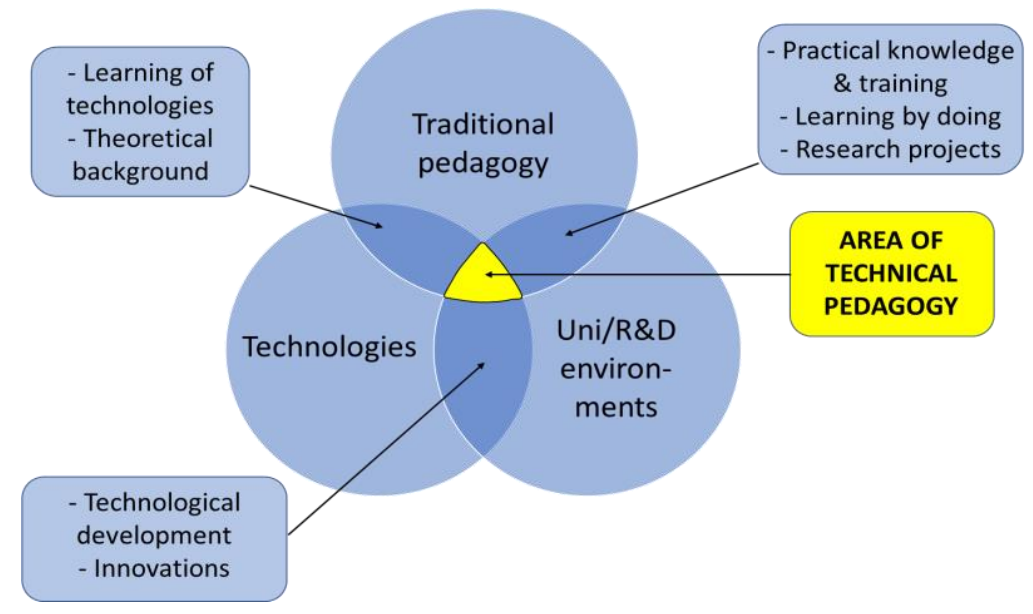

Fig. 10. Factors for the model

Figure 10 presents three foundations for the model; traditional pedagogy, technologies and university and its R\&D environments. Traditional pedagogy is included in the professional teacher skills needed through the proper pedagogical education of a professional teacher. Technologies (e.g. additive manufacturing) present the topics that need to be learnt and integrated into the learning process. This includes the usual technological development (learning of the new technologies) and different innovations. University and R\&D environments present different places (e.g. laboratories and learning environments) where practical learning can take place. The overlapping areas (see Figure 10) between the three foundations presents the functions which the overlapping enables. Pedagogy and technologies enable the learning of the necessary theoretical background for the desired technology. Pedagogy and environments enable the 
practical learning, especially through learning by doing. This can also be a substrate for research projects when the university $R \& D$-functions are involved. Technologies and environments enable the development of the technologies. This shows that the learning process can also lead to new innovations. In the middle of all is the birthplace for the idea and model of technical pedagogy (see Figure 10). It combines the three foundations and the overlapping areas by giving the space for new kind of teaching and learning model. According to the experience of the author, by recognizing the so-called building blocks for any pedagogical model, it helps to orientate the planning to right direction. In this case, these three factors are the most important starting points.

By identifying the factors behind engineering education, pedagogy and the crossing point between the factors (see Figure 10), the model of technical pedagogy is created with AM as the target technology. Figure 11 presents the structure of technical pedagogy with AM perspective.

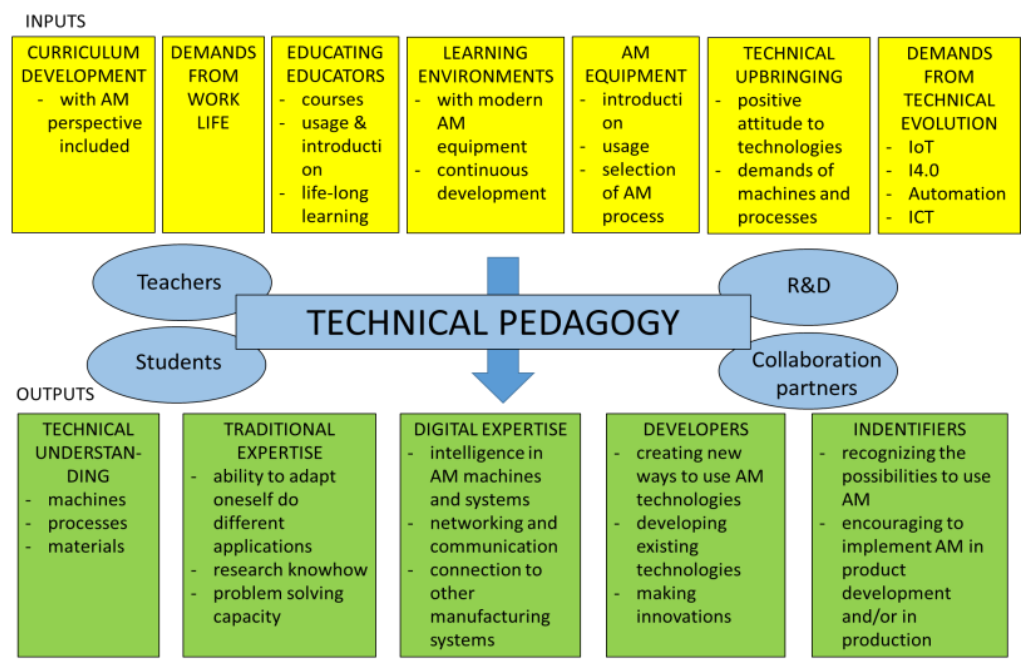

Fig. 11. The model of technical pedagogy

Figure 11 presents a model for arranging technical education in different areas concerning certain technology, in this case AM. The model:

- Consider necessary factors for implementation the teaching of AM

- Helps to draft the strategy for arranging the education of the technology

- Works as a checklist for planning the actual implementation (e.g. course)

It offers a platform for understanding what technical education requires and it can be applied to different areas of engineering technologies.

The model of technical pedagogy (see Figure 11) is based on the relationship of inputs and outputs which are the factors the education requires in order to produce a desired result. In this case, the advanced AM education is the target. The inputs (see Figure 11) are the factors that need to be arranged when planning to teach and learn 
certain modern technology such as AM. The inputs (see Figure 11) combine the curriculum work and competences to the learning environment arrangement and they include the need for arranging education and training to the educators (teachers). This includes the demands from work life (through curriculum work and work-life connections). The modern aspect of technological evolution especially from the smart manufacturing perspective is also included through industry 4.0 [27]. This is connected to the on current Lapland UAS digital laboratory environment which concentrates on smart manufacturing systems. Technical evolution (see Figure 11) factors in the model work as enablers in giving the possibility to include them in the education. Based on the experience of the main author, this description of the technical pedagogy must contain the upbringing aspect. The educational provider must enable a positive atmosphere towards the subject at hand. By creating a learning environment or event that motivates the student to use technology in the studies, it will boost their level of technical skills.

In the middle of the model (see Figure 11) are the operators. The operators are the students, teachers, the R\&D department of universities and collaboration partners, who function within the model. Collaboration partners are e.g. work-life employers, research partners or certain technology collaborators (such as AM equipment manufacturers). These operators enable the model (see Figure 11); teachers and R\&D department function mainly as the builders of the infrastructure for the inputs. The students are the target group for this model, collaboration partners function on both sides; they partially enable the substrate for the inputs but are also the customers since graduating students take their expertise from the technology to companies and industry.

The outputs (see Figure 11) are the factors need to be considered when arranging the education. The outputs present the desired competences and targeted learning objectives which can be integrated into the implementation of AM courses. When these are in order, the model produces solutions to introduce new technology to students. These solutions (outputs) help to identify the desired learning objectives in broader perspective than just as learning objectives in individual courses. By using this model, the educators and institutions can:

- Implement desired technical subjects into the engineering curriculum (model work as a checklist for planning the education)

- Understand what is required to implement technical subject to engineering through traditional pedagogy (inputs)

- Understand what is required to arrange the practical learning situation (e.g. courses, laboratories) (outputs)

- Create technology-based competences and learning objectives (outputs)

- Find out solutions to be used in introducing new technologies to students (outputs)

- List all the operators that work within the model

Technical pedagogy is an important tool especially for engineering education since it can be used to keep the education up to date according to the general technical development. The development of education through a traditional curriculum process does not always consider the details in certain technology. For example, [28] emphasizes the importance of curriculum development to reach the required quality of traditional engineering education set by the needs of work-life and industry. With this model, the 
technical details can be considered and implemented, especially when drafting the competences and learning objectives in curriculum work.

\section{Conclusion}

Implementing engineering education has always leaned to the usage curriculum, learning objectives and competences. This has been the main guideline always since curriculum offers some kind of standard how to produce experts in their own field. 3D printing has already shaken the manufacturing and educational sectors with the versatility of the technology and fast development pace. The sectors are now detecting the real possibilities of the AM technology. Narrowing the gap between the technological development and education is the most important when knowledge about AM is transferred to industry and companies. The change is already happening but it must be ensured that the quality of the knowledge is sufficient and better targeted to certain areas of the society (e.g. certain manufacturing sector).

Creating and updating curriculum, competences and learning objectives are the most important task to be done when the AM knowledge is transferred to work-life from engineering education. When planning and updating a curriculum, the basic curriculum process can be used for including certain technology in it through implementing the features of the technology to the planning process stages properly. The curriculum process with AM perspective presented in this study can be used in in implementing AM into any engineering education since it offers a clear process model for the curriculum work. This helps the educators in their curriculum development work when technical aspects (e.g. AM) are implemented into the curriculum.

In order to implement the learning of AM in practice, the nature of the learning must be understood. The inversely proportional learning path of $A M$ presented in this study show how to arrange AM courses taking the nature of AM requirements into consideration with respective to the learning process of a student. This presentation of AM learning helps the educators to plan the pedagogical path in AM courses in order to achieve efficient learning for the engineering student.

The model of technical pedagogy presented in this study shows a tool for bringing the traditional curriculum work and the introduction of new technologies together. The model brings the three most common factors of engineering education (traditional pedagogy, technologies and the environments of the university and its R\&D operations) together. Educators can use the model as a checklist when planning the education of technical subject, such as AM. This model helps to develop a strategy implementing AM into the technical education program by showing which factors must be considered in the implementation stage of the education. The results of this study can be used in planning engineering education, especially through curriculum development with specific technology such as AM.

3D printing can be seen as the next industrial revolution but it must also be seen as a reformer of technical education. This requires the change of attitudes, investing in modern learning environments with several AM technologies and the motivation to change curricula. 


\section{$5 \quad$ Acknowledgement}

The authors are grateful to LUT University (LUT) and Lapland University of Applied Sciences (Lapland UAS) for enabling the research substrate for this paper.

\section{References}

[1] I. Gibson, D. Rosen, and B. Stucker, Additive manufacturing technologies. 3D printing, Rapid prototyping and direct digital manufacturing, $2^{\text {nd }}$ ed. New York: Springer Science + Business Media, 2015. [E-book] Available: Springer e-book. https://doi.org/10.1007/ 978-1-4939-2113-3_16

[2] SFS-EN ISO / ASTM 52900:2017, "Standard Terminology for Additive Manufacturing General Principles - Terminology," 24 Feb., 2017.

[3] Wohlers Associates Inc., Wohlers report 2017 - history of additive manufacturing, Wohlers Associates Inc., 2017.

[4] A. Kircheim, H-J. Dennig and L. Zumofen, "Why education and training in the field of additive manufacturing is a necessity - The right way to teach students and professionals" In Proc. Industrializing Additive Manufacturing - Proceedings of Additive Manufacturing in Products and Applications - AMPA2017, 2017, pp. 329-336. https://doi.org/10.1007/9783-319-66866-6 31

[5] Universities of Applied Sciences Act 932/2014, 4§. Finlex Data bank. 2014. [Online]. Available: https://finlex.fi/fi/laki/ajantasa/2014/20140932. [Accessed Jun. 10, 2020].

[6] H. Kangastie and P. Mastosaari, Organizing learning - Teacher guide. Publications of Lapland UAS, category C 1, 2016.

[7] F. Sheikh. Webinar, Topic: "FORM 2 - Live product walkthrough." Formlabs, Feb. 20, 2019.

[8] Gartner, "Hype cycle for 3D printing," July 13, 2018. [Online]. Available: https://www.gartner.com/doc/3881825/hype-cycle-d-printing-. [Accessed Feb. 22, 2019].

[9] Gartner, "Gartner hype cycle," 2019. [Online]. Available: https://www.gartner.com/en/research/methodologies/gartner-hype-cycle. [Accessed Sept. 24, 2019]. https://doi.org/10. $1109 /$ temscon.2019.8813649

[10] Wohlers Associates Inc., Wohlers report 2017. - full report, Wohlers Associates Inc., 2017.

[11] E. Pei, M. Monzón, and A. Bernard (editors), Additive manufacturing - Developments in Training and education. Switzerland, Springer International Publishing, 2018. [E-book] Available: Springer e-book.

[12] Wohlers Associates Inc., Wohlers report 2017 - applications, Wohlers Associates Inc., 2017.

[13] T. Snyder, et al., "3D Systems' Technology overview and New applications in Manufacturing, Science and Education," 3D printing and Additive Manufacturing, vol. 1, no. 3, September, 2014. [Online serial]. Available: https://www.liebertpub.com/doi/full/10.1089/ 3dp.2014.1502/. [Accessed: Feb 21, 2019].

[14] K. Brans, "3D Printing, a maturing technology," in Proc. 11th IFAC Workshop on Intelligent Manufacturing Systems '05, 2013, pp. 468-472.

[15] M. Mebolt and C. Klahn (editors), Industrializing Additive Manufacturing-Proceedings of Additive Manufacturing in Products and Applications - AMPA2017. Switzerland, Springer International Publishing, 2017. [E-book] Available: Springer e-book. https://doi.org/10. $\underline{1007 / 978-3-319-66866-6}$ 
[16] F. Tunca and Ö.N. Kanat, "Harmonization and simplification roles of technology transfer offices for effective university-industry collaboration models," Procedia Computer Science, vol. 158, October, 2019. [Online serial]. Available: https://www.sciencedirect.com/science/article/pii/S1877050919312232. [Accessed Oct. 29, 2019]. https://doi.org/10.1016/ i.procs.2019.09.063

[17] X. Shi, Y. Wu and D. Fu, "Does University-Industry collaboration improve innovation efficiency? Evidence from Chinese Firms," Journal of Economic Modeling, May, 2019. [Online serial]. Available: https://www.sciencedirect.com/science/article/abs/pii/S02649993173185 76. [Accessed Oct. 29, 2019]. https://doi.org/10.1016/j.econmod.2019.05.004

[18] A. Ala-Poikela, Lapland universities employer survey - report. Lapland University Education and Development Services, 2015.

[19] C. Seidel and R. Schätz, Continuing education and part-time training on Additive Manufacturing for people in employment - an approach focused on content-related and didactical excellence. Additive manufacturing - Developments in training and education. Swizerland, Springer International Publishing, 2019. [E-book] Available: Springer e-book. https://doi. org/10.1007/978-3-319-76084-1_2

[20] Lapland University of Applied Sciences. Guidelines for designing curriculum 2017. Lapland UAS, 2015.

[21] M.F. Ercan, D. Sale, N. Kristian, "Innovative Curriculum to Enhance the Learning Experience of Electrical and Mechanical Engineering Students," International Journal of Engineering Pedagogy (iJEP), vol 6, no. 3, 2016. [Online serial]. Available: https://online-journals.org/index.php/i-jep/article/view/5765 /. [Accessed Sept. 9, 2019]. https://doi.org/10. 3991/ijep.v6i3.5765

[22] P. Auvinen et. al. Recommendation for the application of National Qualifications Framework (NQF) and the common general competences of qualifications in Universities of Applied Sciences, Arene, 2010.

[23] S. Ford and T. Minshall, "Where and how 3D printing is used in teaching and education," Additive manufacturing, 25, October, 2019. [Online serial]. Available: https://www.sciencedirect.com/science/article/pii/S2214860417304815. [Accessed March 8, 2019]. https:// doi.org/10.1016/j.addma.2018.10.028

[24] M. Karyotaki and A. Drigasm, "Latest trends in problem solving assessment," International Journal of Recent contributions from Engineering, Science \& IT (iJES), vol. 4, no. 2, 2016. [Online serial]. Available: https://online-journals.org/index.php/i-jes/article/view/5800/. [Accessed Aug. 21, 2019]. https://doi.org/10.3991/ijes.v4i2.5800

[25] Encyclopedia Britannica, "Technical education", 2019. [Online]. Available: https://www. britannica.com/topic/technical-education. [Accessed Nov. 4, 2019].

[26] T. Rüütmann and H. Kipper, "Klagenfurt School of Engineering Pedagogy by Adolf Melezinek as the Basis of Teaching Engineering," International Journal of Engineering Pedagogy (iJEP), vol. 6, no. 3, 2016. [Online serial]. Available: https://onlinejournals.org/index.php/i-jep/article/view/5949/. [Accessed Aug. 27, 2019]. https://doi. org/10.3991/ijep.v6i3.5949

[27] Oracle, "The 4th Industrial Revolution: A Primer for Manufacturers", 2019. [Online]. Available: https://cloud. oracle.com/opc/saas/indmftg/reports/the-fourth-industrial-revolution-report.pdf. [Accessed Nov. 5, 2019].

[28] H.J.R. Terano, "Development of integrated curricula for the master of engineering programs using the CDIO framework," International Journal of Engineering Pedagogy (iJEP), vol 9, no. 3, 2019. [Online serial]. Available: https://online-journals.org/index.php/i-jep/article/view/10112. [Accessed Jun. 19, 2020]. https://doi.org/10.3991/ijep.v9i3.10112 


\section{Authors}

Mr. Ari Pikkarainen, M.Sc (Tech.) is working as a senior lecturer in mechanical engineering degree in Lapland University of Applied Sciences (Lapland UAS) in Kemi, Finland. He has been working also as a mechanical designer in different areas such as steel- and paper industry. Pikkarainen acted as the main responsible teacher (guiding a team of teachers and R\&D personnel) in renewing Lapland UAS mechanical engineering curriculum in 2014-2017. He is currently doing his D.Sc. (Tech.) studies at LUT University and his doctoral thesis is about the connection between education and 3D printing. His dissertation is expected to be finished in summer 2021.

Professor Heidi Piili, D.Sc. (Tech.) is working as a professor and team leader in the field of laser processing and additive manufacturing in Research Group of Laser Materials Processing and Additive Manufacturing, School of Energy Systems, LUT University in Lappeenranta, Finland. Piili was working within industrial additive manufacturing during year 2017 at Electro Optical Systems (EOS) Finland. Piili has more than 18 years' experience of laser processing (cutting, micro/mill processing, welding etc.) of various different materials. Her doctoral thesis in 2013 was about characterization and mathematical modeling of interaction between laser beam and material. Piili has been working more than 11 years with additive manufacturing, mostly concentrating to powder bed fusion of metallic materials. At the moment, she participates to national and international projects (academic and industrial) and also educates additive manufacturing and laser technology. She has more than 120 international publications in field of laser technology and additive manufacturing and her h-index is 11 (Google Scholar) and 8 (Scopus).

Article submitted 2020-04-15. Resubmitted 2020-07-02. Final acceptance 2020-07-02. Final version published as submitted by the authors. 